WM'03 Conference, February 23-27, 2003, Tucson, AZ

\title{
PACKAGING AND DISPOSAL OF A RADIUM-BERYLLIUM SOURCE USING DEPLETED URANIUM POLYETHYLENE COMPOSITE SHIELDING
}

\author{
Keith Rule \\ Princeton Plasma Physics Laboratory \\ Paul Kalb, Pete Kwaschyn \\ Brookhaven National Laboratory
}

\begin{abstract}
Two, $111 \mathrm{GBq}$ (3 Curie) radium-beryllium (RaBe) sources were in underground storage at the Brookhaven National Laboratory (BNL) since 1988. These sources originated from Princeton Plasma Physics Laboratory (PPPL) where they were used to calibrate neutron detection diagnostics. In 1999, PPPL and BNL began a collaborative effort to expand the use of an innovative pilot-scale technology and bring it to full- scale deployment to shield these sources for eventual transport and burial at the Hanford Burial site. The transport/disposal container was constructed of depleted uranium oxide encapsulated in polyethylene to provide suitable shielding for both gamma and neutron radiation. This new material can be produced from recycled waste products (DU and polyethylene), is inexpensive, and can be disposed with the waste, unlike conventional lead containers, thus reducing exposure time for workers. This paper will provide calculations and information that led to the initial design of the shielding. We will also describe the production-scale processing of the container, cost, schedule, logistics, and many unforeseen challenges that eventually resulted in the successful fabrication and deployment of this shield. We will conclude with a description of the final configuration of the shielding container and shipping package along with recommendations for future shielding designs.
\end{abstract}

\section{INTRODUCTION}

Two $111 \mathrm{GBq}$ (3-Curie) radium-beryllium sources were transferred from the Oak Ridge National to Laboratory to PPPL, in the late 1970's, for the performance of neutron studies and instrument calibrations of sophisticated diagnostic equipment in support of our fusion energy research. In 1987, these sources were no longer needed for their intended use and were offered to other potential users, however no other user was identified. As such, an interim safe storage or disposal option was needed. A safe storage option was chosen due to the lack of a clear disposal option. The sources were transferred to the Brookhaven National Laboratory (BNL) in 1988 and were placed in an underground storage vault. In 1996, PPPL initiated efforts for disposal of these sources at the Hanford Burial site. At this time Hanford burial regulations considered the RaBe sources to be transuranic and would not accept them for burial. In 1998, Hanford removed radium from their criteria as a transuranic and correctly identified it as a non- transuranic radionuclide with assigned criteria for burial. The disposal option was now possible but not without careful planning and a lengthy process to develop an acceptable shielding and packaging configuration to facilitate transportation and burial.

\section{TRANSPORTING TO BNL FOR STORAGE}

The two sources were small in physical size, but with their six Curies of activity they pose a considerable challenge for handling, transportation and burial. The sources are contained within 
WM'03 Conference, February 23-27, 2003, Tucson, AZ

double encapsulated cylindrical monel containers with an approximate diameter of $3 / 4$ " and length of 1.5 inches. They produce $7 \mathrm{E}+7$ neutrons per second with associated unshielded dose rates of approximately $60 \mathrm{mSv} / \mathrm{hr}(6 \mathrm{R} / \mathrm{hr})$ gamma and over $120 \mathrm{mSv} / \mathrm{hr}(12 \mathrm{R} / \mathrm{hr})$ neutron. In August 1987 , the sources were placed within a $2 \mathrm{R}(1)$ inner containment vessel. This vessel is required to be used in conjunction with a Specification container. A $2 \mathrm{R}$ container is a schedule 40 pipe with specified maximum diameter and length. In Figure 1, below, the $2 \mathrm{R}$ container has a 2" inside diameter with a length of 6 inches. The bottom is a welded flange with the opening having a screw-type cap.

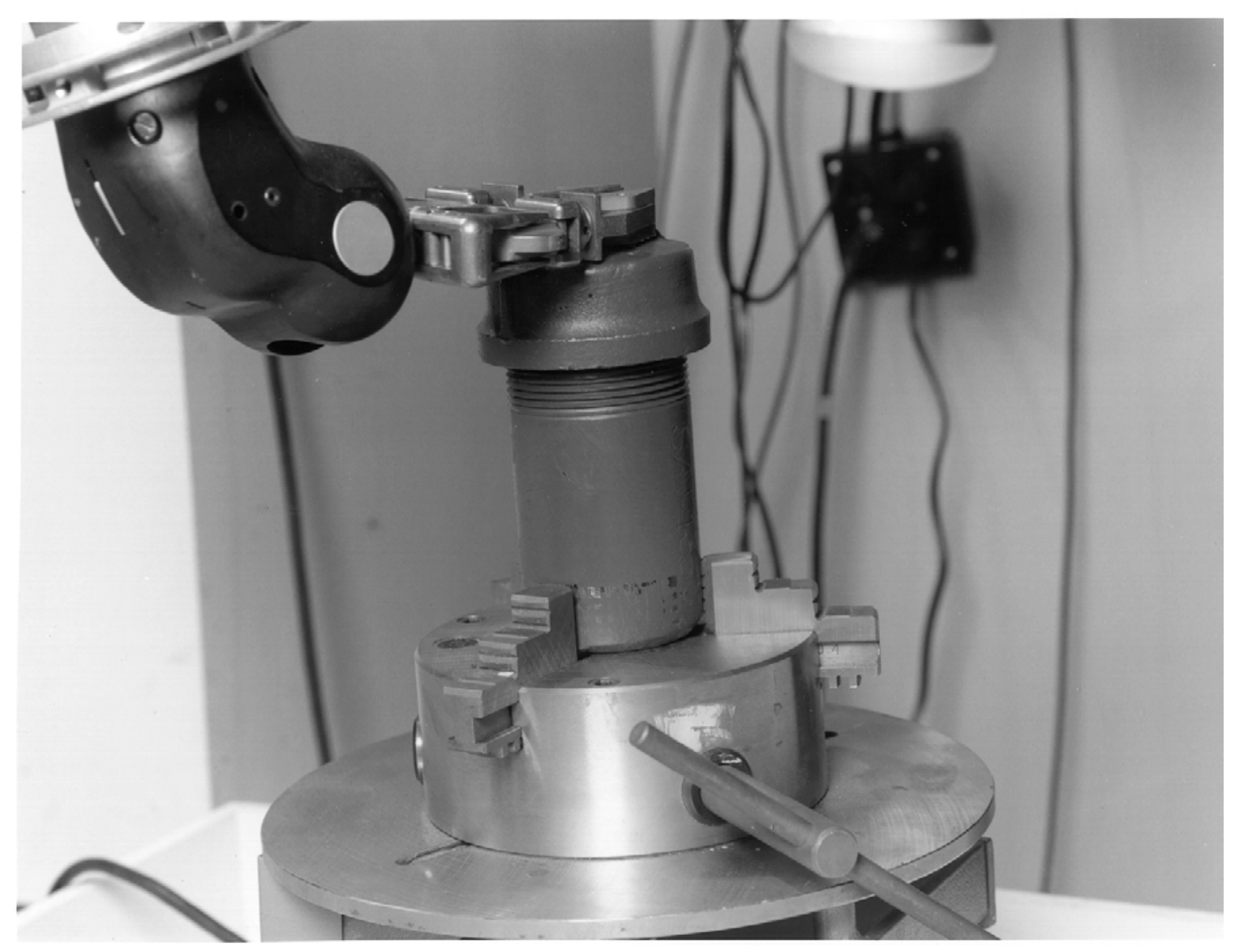

Figure 1 - 2R Container for sources

The $2 \mathrm{R}$ vessel was then placed within a steel and lead storage pig weighing 1800 pounds. This greatly reduced the dose rates to $90 \mathrm{uSv} / \mathrm{hr}(9 \mathrm{mRem} / \mathrm{hr})$ gamma and $0.9 \mathrm{mSv}(90 \mathrm{mRem} / \mathrm{hr}$ ) neutron at one meter, which significantly improved the handling and transportation of the sources.

This lead storage pig was then placed within a 55 gallon drum and subsequently inserted into a Specification 20-WC-5 container (2) in preparation for transportation. The $222 \mathrm{GBq}$ (6 Curies) of radium exceeded the DOT Type A limit in 1988. Consequently, a "Type B" container was needed to transport the sources to BNL. The 20-WC-5 container is a DOT specification container for transportation of quantities in excess of Type A. The weight capacity of this container is 4,000 pounds; therefore the lead pig with a weight of 1800 pounds is well within the weight constraint of this specification container. Upon receipt at BNL, the lead pig was placed within a concrete in-ground cylinder to a depth of approximately 6 feet for long-term storage. 
During the mid to late 1990's many sites were receiving increased pressure to evaluate the potential environmental impacts of the various radiological hazards that exist at their facilities with special emphasis on "legacy" materials. Brookhaven initiated a special task force to evaluate their laboratory facilities. During this review, the PPPL RaBe sources, along with others that were interned in a similar manner, were considered high priority to remove and dispose.

In 1998, the Hanford Waste Acceptance Criteria underwent a complete review and revision with input from many generators and on-site representatives. As a result of this review, radium was removed from the list as a "transuranic" and listed as an approved radionuclide for disposal in the low-level burial grounds according to the published criterion. This facilitated a request for burial, but not without difficulty. The acceptable levels for burial of radium were still well below the activity of the sources. The Category 1 and Category 3 (3) limits are $6.29 \mathrm{MBq} / \mathrm{m}^{3}$ $\left(1.7 \mathrm{E}-4 \mathrm{Ci} / \mathrm{m}^{3}\right)$ and $1591 \mathrm{MBq} / \mathrm{m}^{3}\left(4.3 \mathrm{E}-2 \mathrm{Ci} / \mathrm{m}^{3}\right)$, respectively. The PPPL RaBe sources exceed both of these limits.

However, through negotiations with the Hanford Waste Acceptance division, a final arrangement was agreed upon to allow disposal of this waste, as long as the following criteria were met: 1) The sources have to be shielded adequately for transportation and should be shielded to less than $1 \mathrm{mSv} / \mathrm{hr}(100 \mathrm{mRem} / \mathrm{hr})$ so that remote handling is not required at Hanford. 2) The sources shall be buried within a high integrity container (HIC). 3) Lead cannot be used to shield the sources; and 4) The shipment must be coordinated to allow for proper selection of the burial location in order to utilize the comprehensive burial pit limits for radium.

\section{A PACKAGING CONCEPT FOR TRANSPORT AND BURIAL}

In 1998, PPPL provided BNL with two Enviralloy EA-50C High Integrity Containers for use in packaging high-activity waste from their medical isotope accelerators. These containers are stainless steel in construction and have an internal volume of 42 cubic feet, weight capacity of $4200 \#$ with an lid opening of 44 inches. Upon first glance, they seemed to be well suited for a large shield insert.

These HICs were originally purchased (at a cost of $\$ 40,000$ each) for the burial of Type B quantities of tritium for our Deuterium-Tritium fusion research program. During the course of the research, a more attractive recycling option was utilized in cooperation with the Savannah River site, which removed the need for these disposal containers. As a result, PPPL provided the containers with a contingency that one of the containers be used to dispose of the RaBe source, in storage at BNL. The original intention, by both parties, was to commingle the RaBe source with the other non-transuranic sources for eventual burial. This concept was not feasible due to dose rates and activity concentrations; therefore one of the HICS was dedicated solely for disposal of the RaBe sources.

The next objective was to select shielding material and design a configuration for the sources to meet Department of Transportation (DOT) and Hanford requirements. As previously mentioned, lead was not an option. The shielding needed to provide significant reduction of both gamma and neutron radiation to less than $1 \mathrm{mSv} / \mathrm{hr}(100 \mathrm{mRem} / \mathrm{hr})$, if feasible. The most prevalent type of shielding in use is for this application is a combination of steel and concrete. The concrete is not as effective for gamma as it is for neutron, but with sufficient thickness it can be cost effective to use concrete with the proper steel support to shield neutron-gamma isotopes. A 
WM'03 Conference, February 23-27, 2003, Tucson, AZ

useful rule of thumb is 24 " of concrete will reduce $\sim 1.25 \mathrm{Mev}$ gamma dose rate to one-tenth of unshielded value. For our sources, this would result in a dose rate of 5-6 mSv/hr $(500-600$ $\mathrm{mRem} / \mathrm{hr}$ ), at the maximum dimension of our HIC, and beyond the weight capacity by $1500-$ 2000 pounds, while not meeting all of our criteria.

Alternatively, an innovative material manufactured from depleted uranium oxide powder microencapsulated in polyethylene was used to fabricate a shielding container for transportation and disposal. This technology was based on microencapsulation and macroencapsulation process systems that were developed and patented by the BNL Environmental Research and Technology Division, for the treatment of radioactive, hazardous, and mixed wastes. $(4,5)$ In this case, the highly dense uranium oxide provides shielding from gamma radiation and the hydrogen contained within the polyethylene serves as a neutron shield. Based on successful pilot-scale testing, loadings of DU as high as $90 \mathrm{wt} \%$ can be achieved. This project represented the first time the technology was scaled up to produce a prototype shielding product for a realworld application.

In 1996, the BNL Environmental Research and Technology Division within the Environmental Science Department, completed bench-scale development of a depleted uranium/polyethylene shielding matrix using a modified extruder-based system. This apparatus facilitates the proper ratio and mixing of materials, and production of the heated matrix in a flowable form so specific shapes or volumes can be filled. When the material cools below its melt temperature $\left(120^{\circ} \mathrm{C}\right) \mathrm{a}$ solid, durable, monolithic product is formed.

Due to the close working relationships of the technology development and waste management organizations of both laboratories, the Waste Management Division at PPPL decided to fund a project that would design and fabricate this full-scale DU/poly shield while utilizing the Enviralloy HIC. Our objectives:

1) Design a shield configuration to fit within the Enviralloy HIC.

2) Reduce dose rates below $100 \mathrm{mRem} / \mathrm{hr}$

3) Demonstrate the concept of the Depleted Uranium Encapsulated in Polyethylene transport/disposal container.

4) Meet all of the DOT and Hanford requirements.

5) Complete the project on-time and within budget.

6) Establish a cost-benefit range for the technology.

\section{WHAT IS A DEPLETED URANIUM POLYETHYLENE COMPOSITE SHIELD}

Depleted uranium (DU) is a residual material that results from the enrichment of uranium ore in the making of nuclear fuel. The U.S. Department of Energy (DOE) maintains large inventories of depleted uranium at several sites. Due to the cost and potential environmental, health and safety concerns in storing this material, DOE has been investigating alternatives to place the material in more stable forms. Beneficial end-use of stabilized depleted uranium oxide powder, such as Polyethylene Encapsulated Depleted Uranium Composites, would reduce overall process costs, eliminate disposal cost, and facilitate secondary applications for this valuable resource.

BNL has conducted extensive research and development on polyethylene microencapsulation (waste is homogeneously distributed within encapsulation matrix) and macroencapsulation technologies (larger size waste particles are surrounded by clean plastic). Binder material is not susceptible to interactions with the waste and thus, formation of a monolithic solid is guaranteed. Recycled polyethylene can be used for processing, providing an inexpensive and productive 
WM'03 Conference, February 23-27, 2003, Tucson, AZ

secondary end-use for this important resource material. The product is durable (compressive strength $>2000 \mathrm{psi}$ ) and exhibits relatively low leachability. In the patented Polyethylene Encapsulated Depleted Uranium Composite, depleted uranium oxide (in this case, $\mathrm{UO}_{3}$ ) is mixed with polyethylene at ratios ranging from $60 \mathrm{wt} \%$ to $90 \mathrm{wt} \%$. A loading ratio of $80 \mathrm{wt} \%$ was selected for the production of the prototype shielding container, based on the balance of shielding requirements and processability.

\section{DESIGNING AND MANUFACTURING THE SHIELD}

PPPL engineers performed calculations to determine the minimum shielding thickness that would provide dose rates within the desired aforementioned criteria. The gamma does rates were the most restrictive. The calculations utilized three different $\mathrm{wt} \%$ values of $\mathrm{DU} /$ poly, $70 \%, 80 \%$ and $90 \%$. The $70 \%$ calculation indicated that a 12.8 " shield thickness was required. This thickness would then require a total diameter of approximately 28 inches to account for shielding around the $2 \mathrm{R}$ vessel. This diameter leaves little room for error when loading the shield within the Enviralloy HIC and was considered unacceptable. Therefore an $80 \mathrm{wt} \%$ concentration was selected which provides for a 9.3" shield thickness.

Envirocare of Utah, Inc has licensed BNL's polyethylene microencapsulation and macroencapsulation technologies. As part of the license agreement, BNL loaned Envirocare its full-scale processing equipment, so the prototype-shielding container was fabricated at the Envirocare waste processing facility in Clive, Utah. The process equipment is shown in Figure 2, below.

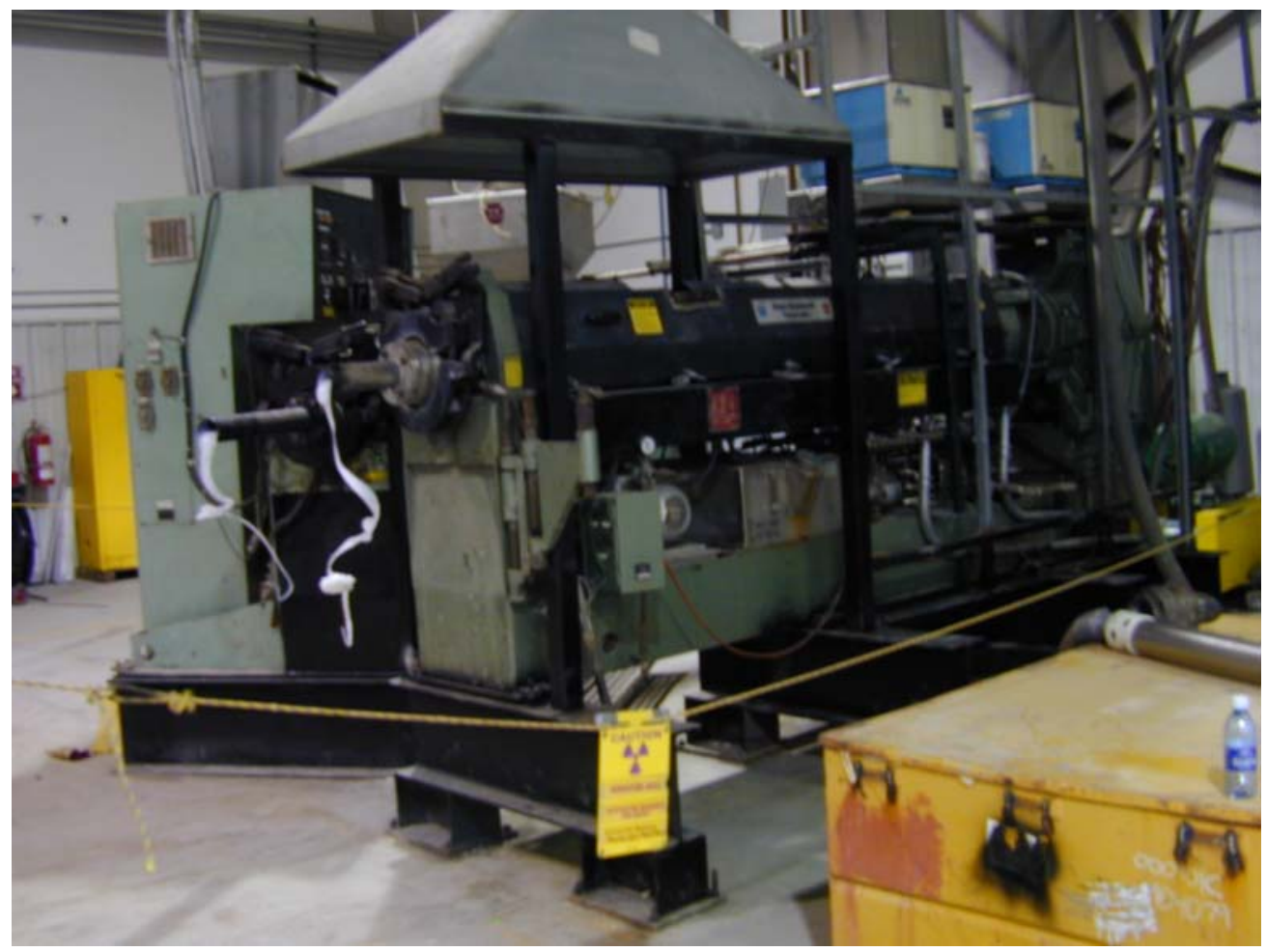

Figure 2. Polyethylene extrusion system used to process DU/poly shield

Pneumatic vacuum conveyors, manufactured by Vac-U-Max, Belleville, NJ, were used to transfer $\mathrm{UO}_{3}$ powder and LDPE pellets to separate extension hoppers on the material feeders. Material feed was accomplished using two dry material feeders (AccuRate Model 610) in 
WM'03 Conference, February 23-27, 2003, Tucson, AZ

concert with a real-time delivery feedback system (Merrick Model 510 loss-in-weight controller). The system controls rate of feed from material hoppers to ensure constant waste/binder ratio as well as total feed rate. A 4.5-inch $(11.4 \mathrm{~cm})$ Davis-Standard single-screw extruder with 2.5-inch $(6.4 \mathrm{~cm})$ output die will be used to process the DUPoly material. Rated output capacity of this extruder is $2000 \mathrm{lb} / \mathrm{hr}(900 \mathrm{~kg} / \mathrm{hr}$.) The extruder is equipped with a twostage vented screw with feed transition and metering sections in the first stage, and vent and metering sections in the second stage to remove any moisture vapor or other volatiles. The molten material was cast in two cylindrical aluminum molds (upper and lower sections of the shipping container), with a specially designed section to accommodate the RaBe source. The extruder composite was then compressed and cooled by convection to ambient temperature, and assembled inside the stainless steel HIC for return shipment to BNL.

In general, processing proceeded as anticipated. Grab samples were taken periodically for density measurements to ensure that the extrudate was well mixed and homogeneous. One problem was observed towards the end of the process run. The extruder barrel vent had plugged with product, preventing the system from removing entrained gas. While no foaming was observable at the time, this half of the mold subsided slightly upon cooling, leaving a small concave "dip" in the surface. This was repaired after arrival at BNL by placing the mold in a large walk-in oven, re-heating to melt temperature and allowing the composite to cool slowly and allow entrained gas to escape. A small gap in the composite material was then filled with polyethylene beads. Several stress cracks were also observed on inspection at BNL and this annealing process also relieved these.

\section{ASSEMBLY -SHIELD, HIC AND SOURCES}

The lead storage cask was removed from the in-ground concrete storage location using slings and a forklift. The dose rates on the exterior of the cask were $0.5 \mathrm{mSv} / \mathrm{hr}(50 \mathrm{mRem} / \mathrm{hr})$ gamma and $3 \mathrm{mSv} / \mathrm{hr}$ (300 mRem/hr neutron). The lead pig was placed inside a large polyethylene container filled with water. This significantly reduced the neutron levels and allowed the use of tooling

with extensions. The bolts were removed from the lead pig lid and the lid was removed using long handled tools and ratchets. The process is shown below in Figure 3. 


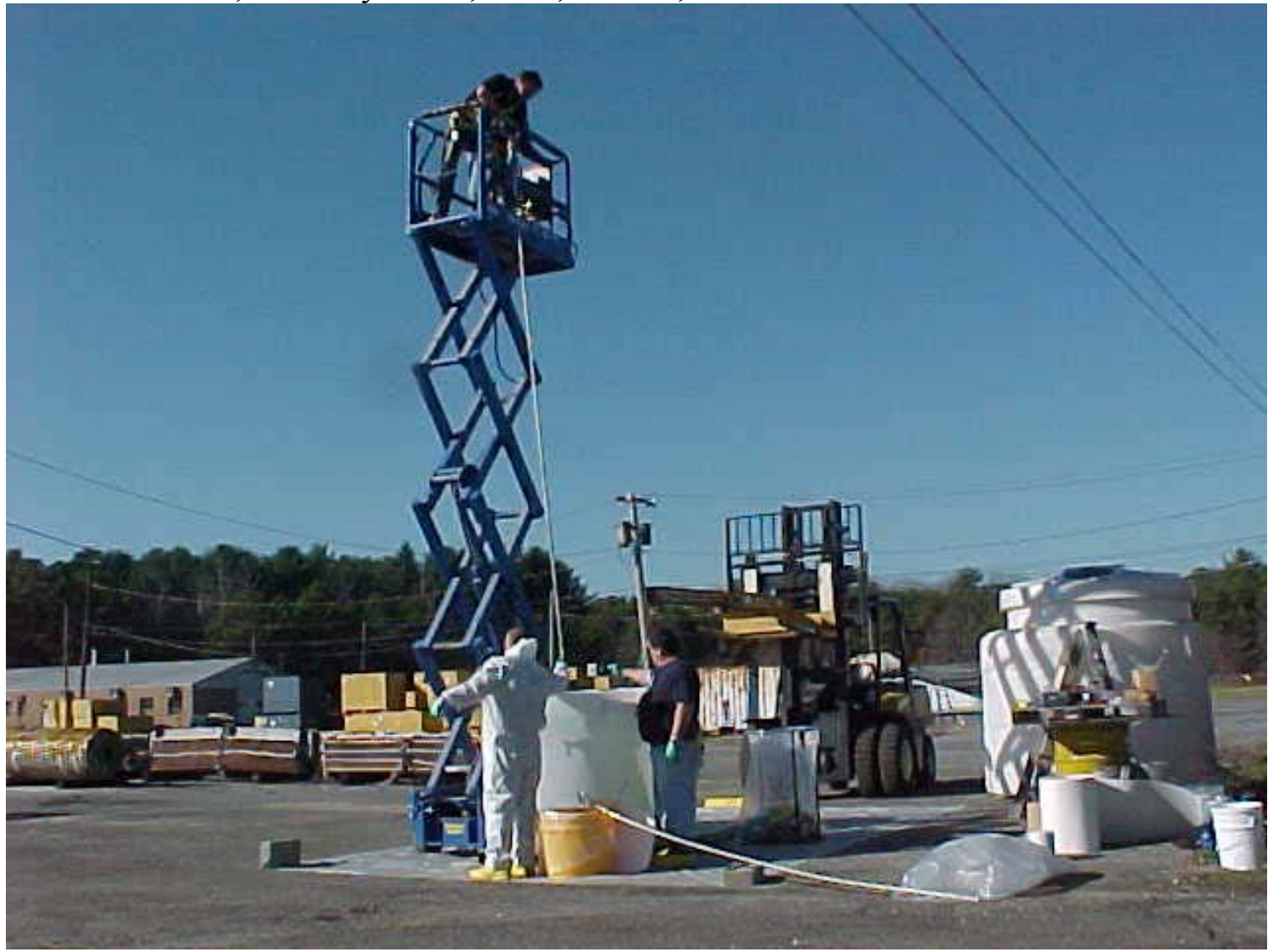

Figure 3 - Removing 2R from Lead Pig

A long handled tool was used to retrieve the $2 \mathrm{R}$ container from within the lead pig and transfer the $2 \mathrm{R}$ to the cast receptacle in the center of the Du/poly shield. The two-part shield was then lifted and assembled to mate the halves to provide the entire shielding capability of the Du/poly matrix.

The shield, which now contains the $2 \mathrm{R}$ with $222 \mathrm{GBq}$ (6 Curies) of radium-beryllium; along with the depleted uranium/polyethylene matrix can be lifted by a crane into the Enviralloy HIC. The shield diameter is approximately 8 inches less in diameter than the interior inside dimension of the HIC. As a result, the HIC was positioned in the center of the HIC and polyethylene beads were poured around the shield to fill the void space and provide additional shielding.

The copper gasket was then installed on the lid seating surface and the lid was installed and torqued to specification. This completed the packaging of the sources within the HIC and placed the sources in their final burial configuration.

\section{DAY OF RECKONING}

The calculations for the shielding thickness indicated that approximately 9 inches of $80 \mathrm{Wt} \%$ $\mathrm{Du} /$ poly were required to reduce the dose rate below $1 \mathrm{mSv} / \mathrm{hr}(100 \mathrm{mRem} / \mathrm{hr})$. The actual calculated dose rate was $0.77 \mathrm{mSv} / \mathrm{hr}(77 \mathrm{mRem} / \mathrm{hr})$. By calculation, only 3 inches of Du/poly was required to reduce the neutron dose rate to less than $1 \mathrm{mSv} / \mathrm{hr}$. Actual surveys on the outside of the Du/poly shield containing the sources were $0.9 \mathrm{mSv} / \mathrm{hr}(90 \mathrm{mRem} / \mathrm{hr})$ gamma and 40 $\mathrm{uSv} / \mathrm{hr}(4.0 \mathrm{mRem} / \mathrm{hr})$ neutron on contact. The gamma dose rates were slightly higher than 
WM'03 Conference, February 23-27, 2003, Tucson, AZ

anticipated but were within our goal of $1 \mathrm{mSv} / \mathrm{hr}$. These dose rates were further reduced when the cask was placed inside the Enviralloy HIC.

The Enviralloy HIC is not a certified transport container. It is designed and tested to meet the requirements for burial but was not tested for DOT requirements. The RaBe sources are Type B quantity according to the "Table of A1 and A2 Values of Radionuclides" in 49 CFR 173.435. In order to transport this container, a Type B cask had to be located and leased that could accommodate the dimension and weight of the container. The maximum payload of this cask is 8,195 pounds. The cask has an internal dimension of 54 inches in diameter and 62 inches in height as compared to the Enviralloy HIC, which is 46.5 inches in diameter by 51 inches in height. A 3-82B Shipping Cask was selected for this shipment and was brokered by Edlow International from ATG, Inc. Kindrick Trucking performed the transportation services and ATG provided a trained cask technician to supervise and perform the loading of the HIC into the 382B shipping cask. Loading is shown below in Figure 4.

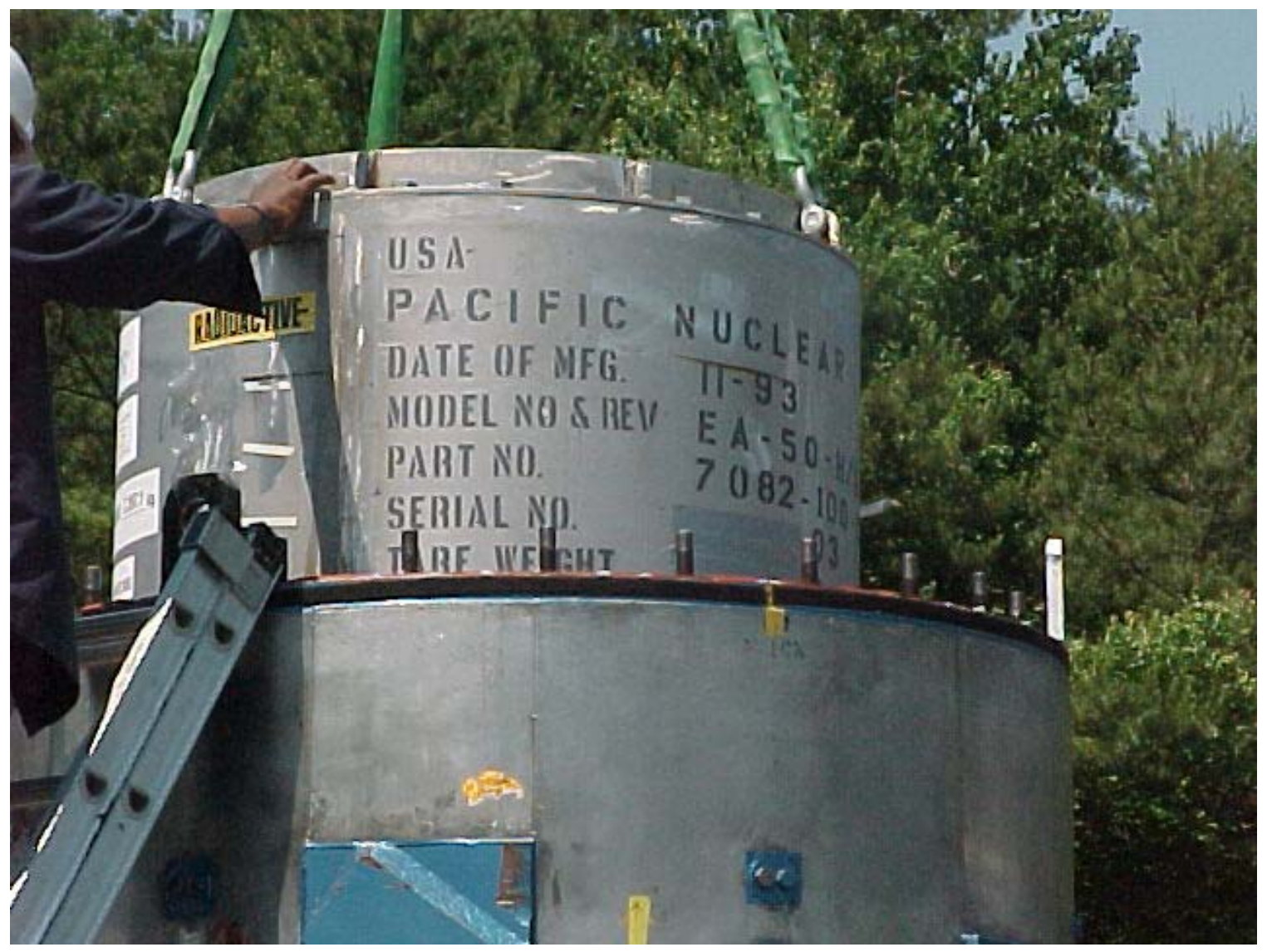

Figure 4 -Loading HIC into 3-82B Cask

The container was loaded into the cask on June 19, 2002 and shipped as a permitted overweight shipment with a combined cask/container weight of 47,078 pounds. Wooden bracing was necessary to prevent any movement of the container during transportation. A leak test was also performed on the cask to ensure integrity of the sealing and torqueing of the closure bolts. The actual loading of the cask was performed in a three hour period without any difficulty. 
WM'03 Conference, February 23-27, 2003, Tucson, AZ

\section{COST SUMMARY}

The depleted uranium had to be purchased due to uncertainties with the "waste" DU that was originally specified for use at the Savannah River Site. Envirocare of Utah had very specific licensing issues with this type of DU and the possibility of impurities from weapons program manufacturing that might violate their license. Therefore, purchase was considered the least expensive manner to avoid further schedule delays and complications. The purchase of this DU, including analysis was $\$ 21,177$.

Engineering, fabrication, skilled labor and administrative costs for the BNL personnel to perform the manufacturing of the shield and packaging of the RaBe sources was $\$ 125,000$. Due to the many lessons learned these costs would be considerably lower for future applications.

The Enviralloy EA-50C was purchased in 1995 at a cost of $\$ 36,270$. The procurement of the services for the transportation cask and trucking through the broker came to a total of $\$ 44,713$. This encompassed delivery from Oak Ridge, TN to Brookhaven (Long Island), a day of loading, transportation to Hanford, unloading at Hanford (one week to unload), and return of the cask and trailer to Oak Ridge, Tennessee. The disposal cost at Hanford was $\$ 1,900$.

The total cost to package, transport and dispose of the two, 3-Curie Radium Beryllium sources was $\$ 229,660$. If future application of this technology is determined to be necessary, the future costs for disposal can be considerably less. The use of a less costly HIC and the use of "free" waste depleted uranium can save $\$ 25-\$ 50 \mathrm{~K}$. The experience gained during the design and fabrication of the shield should provide a minimum of $\$ 60 \mathrm{~K}$ in additional savings. We believe the expected cost to manufacture a shield along with the proper packaging and transportation of a Type B quantity legacy sources(s) can be accomplished for approximately $\$ 120 \mathrm{~K}$.

Subsequent to this project, Hanford revised their Waste Acceptance Criteria and now accepts the burial of selected sources within lead shielding packaging.

\section{ACKNOWLEDGEMENTS}

We would like to acknowledge the efforts of the following collaborators and individuals who brought this project to the successful conclusion that we were striving for.

Alan Erickson - Envirocare of Utah, Steve Elwood and Scott Larson - PPPL, and our DOE supporters - Jeff Makiel and Jerry Faul DOE-PAO,

This work is supported by the US. DOE under contract DE-AC02-98CH10886

\section{REFERENCES}

1. 49 CFR 178. 360 - Specification 2R; Inside containment vessel

2. 49 CFR 178.362 - Specification $20 \mathrm{WC}$ wooden protective jacket

3. Hanford Waste Acceptance Criteria - HNF -EP-0063, Rev. 7

4. Adams, J.W., P.R. Lageraaen, P.D. Kalb, and B.R. Patel, "Polyethylene Encapsulation of Depleted Uranium Trioxide", Emerging Technologies for Hazardous Waste Management 8, D.W. Tedder, F.G. Pohland, eds., Plenum Publishers, New York, 2000

5. Kalb, P.D., J.W. Adams, P.R. Lageraaen, and C. R. Cooley, "DUPoly Process for Treatment of Depleted Uranium and Production of Beneficial End Products" U.S. Patent No. 6,030,549 (February 29, 2000) 